\title{
EXPRESSION OF Mycobacterium tuberculosis RpsA IN Mycobacterium smegmatis INCREASES SUSCEPTIBILITY TO PYRAZINAMIDE
}

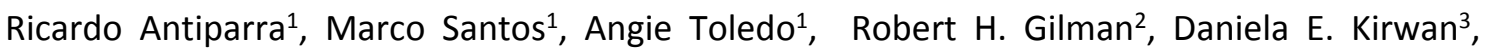
Patricia Sheen ${ }^{1}$, Mirko Zimic ${ }^{1 *}$

${ }^{1}$ Laboratorio de Bioinformática, Biología Molecular y Desarrollos Tecnológicos. Laboratorios de Investigación y Desarrollo. Facultad de Ciencias y Filosofía. Universidad Peruana Cayetano Heredia. Lima, Perú.

2 Department of International Health. Johns Hopkins Bloomberg School of Public Health.

615 North Wolfe St., Room 5515, Baltimore, MD 21205, USA.

${ }^{3}$ Infection and Immunity Research Institute, St George's, University of London. London, UK

* Corresponding Author:

Dr. Mirko Zimic

Laboratorio de Bioinformática, Biología Molecular y Desarrollos Tecnológicos. Laboratorios de Investigación y Desarrollo. Facultad de Ciencias y Filosofía. Universidad Peruana Cayetano Heredia.

Av. Honorio Delgado 430, San Martín de Porres, Lima 31, Peru

Tel: +511 3190000 ext. 233264 


\section{ABSTRACT}

Pyrazinamide (PZA) is one of the most important drugs used in combined antituberculous therapy. After the drug enters Mycobacterium tuberculosis it is hydrolyzed by pyrazinamidase (PZAse) to the bactericidal molecule pyrazinoic acid (POA). Ribosomal protein S1 (RpsA) was recently identified as a possible target of PZA based on its binding activity to POA and capacity to inhibit trans-translation. However, its role is not completely understood.

It has been proposed that Mycobacterium smegmatis RpsA is not capable of binding POA, unlike M. tuberculosis RpsA. This may be due to the different amino acid sequence in the carboxy- terminal region of the two molecules: in M. smegmatis RpsA it is much closer to the sites that may interact with POA than in M. tuberculosis RpsA. These differences could be contributing, along with the presence of highly active POA efflux, to the natural resistance to PZA in $M$. smegmatis.

To further understand the mechanisms of action of PZA and the role of RpsA in PZA susceptibility, we evaluated the effect of complementing $M$. tuberculosis RpsA expression in $M$. smegmatis using pNIT mycobacterial non-integrative expression vector and then performed a PZA susceptibility test determining the minimum inhibitory concentration (MIC) of PZA. It was expected that chimeric ribosomes comprising $M$. tuberculosis RpsA may be present and may affect PZA susceptibility.

Our results showed a reduction in PZA MIC in $M$. smegmatis complemented with overexpressed $M$. tuberculosis RpsA compared to non-overexpressed $M$. smegmatis (468 $\mu \mathrm{g} / \mathrm{mL}$ and $>7500 \mu \mathrm{g} / \mathrm{mL}$ respectively).

Keywords: Tuberculosis, Pyrazinamide, RpsA, POA, Mycobacterium smegmatis. 


\section{INTRODUCTION}

Pyrazinamide (PZA) is one of the most important drugs in the treatment of tuberculosis (TB), being used in both first and second line regimens. It is uniquely effective against slowly dividing sub-populations of bacteria in TB infection, and its inclusion in first-line treatment regimens makes it possible to shorten the duration of treatment from 9 to 6 months (1). PZA susceptibility has been associated with clinical outcomes and although testing for resistance is recommended, this is not universally done due to technical challenges (2).

PZA is a pro-drug that enters Mycobacterium tuberculosis by passive diffusion. In the cytoplasm, PZA is converted by the enzyme pyrazinamidase (PZAse) to its active form, pyrazinoic acid (POA). The POA is then expelled out of the mycobacterium by an efflux mechanism. If the $\mathrm{pH}$ of the extracellular environment is acidic, the POA is protonated to $\mathrm{POAH}$, re-enters the cell, and the proton is released into the cytosol. This cycle repeats itself, causing an intra-cellular accumulation of $\mathrm{POA}$ and a reduction in the $\mathrm{pH}$ of the cytoplasm. This leads to a lethal alteration of membrane permeability; however, the exact mechanism by which this occurs is not yet known (3). It is important to note that other recent studies found that extracellular acid $\mathrm{pH}$ is not required in order for PZA/POA achieve its lethal effect $(4,5,6)$. This confirms that the real mechanism of action of PZA is actually more complicated than previously thought, and further research is required.

Mechanisms of resistance to PZA in M. tuberculosis have been mostly associated with the loss of PZAse activity due to mutations in the pncA gene (pncA mutations in $>80 \%$ of clinical isolates) $(7,8,9)$. However, there are strains of $M$. tuberculosis that are resistant to PZA yet have active PZAse. The mechanism by which these strains are resistant to PZA is not fully known, although several studies suggest the involvement of other target proteins $(10,11,12)$. 
In contrast to M. tuberculosis, Mycobacterium smegmatis is naturally resistant to PZA. While it actively produces POA through two PZAse enzymes (13), it was shown that in M. smegmatis POA is pumped into the extracellular environment 900 fold faster than in M. tuberculosis, preventing POA from accumulating intracellularly at a minimal required critical concentration, and consequentially from exerting any lethal effect on the mycobacterium (14).

Recent studies have identified the ribosomal protein S1 (RpsA) as a probable target of POA $(15,16)$. RpsA is a protein involved in the ribosomal trans-translation process, which has been associated with bacterial survival in states of stress, bacterial virulence, and nutrient recovery in periods of deprivation. Blocking trans-translation prevents the recovery of stalled ribosomes and increases the accumulation of toxic or harmful proteins, causing cell death under conditions of metabolic stress (17). The same study used microcalorimetry to show that in contrast, $M$. smegmatis RpsA protein is not capable of binding POA. Even though both $M$. tuberculosis and M. smegmatis RpsA proteins share a high percentage of amino acid identity, some key differences exist, mainly in their terminal carboxyl region that may affect their capacity to bind to POA and thus susceptibility to PZA.

In the present study, the Rv1630 gene encoding the M. tuberculosis RpsA protein was cloned in the mycobacterial non-integrative vector pNIT and expressed in M. smegmatis $\mathrm{mc}^{2} 155$. PZA susceptibility was then evaluated in this genetic variant of $M$. smegmatis compared to the native strain. Our hypothesis is that the genetic variant of $M$. smegmatis would have a subpopulation of chimeric ribosomes incorporating M. tuberculosis RpsA able to bind POA that may inhibit trans-translation, and potentially affect the susceptibility to PZA. 


\section{METHODS}

\section{Bacterial strains and growth conditions}

Escherichia coli Novablue was routinely grown in Luria Bertani (LB) medium for its use in DNA cloning procedures. Mycobacterium smegmatis $\mathrm{mc}^{2} 155$ was grown at $37^{\circ} \mathrm{C}$ in Middlebrook (MB) $7 \mathrm{H} 9$ liquid medium or on MB $7 \mathrm{H} 10$ agar supplemented with $0.5 \%(\mathrm{v} / \mathrm{v})$ glycerol and $0.05 \%(\mathrm{v} / \mathrm{v})$ Tween 80 . When required, kanamycin $(20 \mu \mathrm{g} / \mathrm{mL})$ was added.

\section{Cloning of the Rv1630 (RpsA) gene from M. tuberculosis H37Rv in the pNIT vector}

The complete Rv1630 gene sequence (Genbank ID: NC 000962.3) was amplified by PCR, digested, and cloned in the mycobacterial expression vector pNIT. The PCR primers contained the restriction sites for Ndel and Hindlll. The primers used are listed in Table 1. Both the pNIT vector and the amplification product of the Rv1630 gene (1446 $\mathrm{pb}$ ) were purified and digested with Ndel and HindIII and then ligated using the DNA T4 ligase for 16 hours at $16^{\circ} \mathrm{C}$. E. coli Novablue cells were transformed by heat shock protocol using $5 \mu \mathrm{L}$ of the ligation reaction. After a short incubation on ice, $50 \mu \mathrm{L}$ of chemically competent E. coli Novablue cells and $50 \mathrm{ng}$ of DNA obtained from the ligation reaction were incubated at $42^{\circ} \mathrm{C}$ for 45 seconds. They were then incubated at $37^{\circ} \mathrm{C}$ for 1 hour and transformants were selected with kanamycin. Recombinant DNA plasmid from transformed E. coli Novablue were extracted using the High Pure RNA Isolation Kit (Roche) following the manufacturer's protocol, and sequenced in sequenced in an $A B I$ PRISM 3100 Genetic Analyzer (Applied Biosystem, Foster City, CA) in both directions.

\section{Expression of the RpsA protein of M. tuberculosis H37Rv in M. smegmatis mc ${ }^{2155}$}

M. smegmatis cells were grown to approximately reach an optical density measured at a wavelength of $600 \mathrm{~nm}\left(\mathrm{OD}_{600}\right)$ of 1 , harvested, and washed 3 times in $10 \%$ gliceroltween 80 , with a reduction in the volume of $10 \%$ glycerol-tween 80 used for each wash. Finally, the washed pellet was resuspended in $1 \mathrm{~mL}$ of the original culture medium (20). $100 \mu \mathrm{L}$ of electrocompetent $M$. smegmatis cells were transformed with $2 \mu \mathrm{L}$ of the 
mycobacterial expression vector pNIT cloned with the gene Rv1630 (RpsA) using electroporation with a gene pluser (Bio-Rad, USA). Electrocompetent $M$. smegmatis cells were pipetted into a $0.2 \mathrm{~cm}$ gap size cuvette with $1 \mu \mathrm{g}$ of plasmid DNA and transformed using a setting of $2.5 \mathrm{kV}$ and $1000 \Omega$. For the expression of the pNIT-RpsA vector, transformed $M$. smegmatis cells were induced with concentrations of $5 \mu \mathrm{M}$ and $10 \mu \mathrm{M}$ of Isovaleronitrile (IVN) in broth medium.

In order to verify successful expression using the pNIT vector in $M$. smegmatis, we cloned Green Fluorescent Protein (GFP) in another pNIT vector. After transforming $M$. smegmatis with pNIT-GFP we induced expression with E-caprolactam at a concentration of $10 \mu \mathrm{M}$. E-caprolactam was used in place of IVN because it can be incorporated into agar plates. We then detected fluorescence using UV excitation $(320 \mathrm{~nm})$ to confirm GFP expression.

\section{qRT-PCR to confirm M. tuberculosis Rv1630 gene transcription in}

\section{M. smegmatis:pNIT/RpsA}

M. smegmatis cells transformed with pNIT/ M. tuberculosis RpsA was grown at $37^{\circ} \mathrm{C}$ in Middlebrook $7 \mathrm{H} 9$ liquid medium supplemented with $0.5 \%(\mathrm{v} / \mathrm{v})$ glycerol and $0.05 \%(\mathrm{v} / \mathrm{v})$ Tween 80 to an $\mathrm{OD}_{600}$ of 0.8 . After inducing with $5 \mu \mathrm{M}$ and $10 \mu \mathrm{M}$ of IVN, cultures were centrifuged at $12,500 \mathrm{rpm}$ at $4^{\circ} \mathrm{C}$ for 20 minutes and the cell pellets were used for RNA extraction.

RNA extraction was performed using the Fast RNA Pro Blue kit (MP Biomedicals) on a Fast Prep-24 instrument (Applied Biosystems) following the manufacturer's instructions. RNA quality and integrity were verified by observing the staining intensity of the major ribosomal RNA (rRNA) bands and any degradation products in a $1 \%$ agarose gel electrophoresis using TBE buffer ( $89 \mathrm{mM}$ Tris, $89 \mathrm{mM}$ boric acid, $2 \mathrm{mM}$ EDTA). Absorbance at $260 \mathrm{~nm}$ of the extracted RNA was measured using a NanoDrop 2000 spectrophotometer (Thermo Fisher Scientific). The extracted RNA was then treated with 
DNAse I (RNAse free): $0.4 \mathrm{U}$ of DNAse/g RNA was added to give a reaction volume of $100 \mu \mathrm{L}$. DNAse buffer $1 \mathrm{X}$ and DEPC water were then added and this was incubated at $37^{\circ} \mathrm{C}$ for 30 minutes followed by DNAse inactivation at $75^{\circ} \mathrm{C}$ for $5 \mathrm{~min}$.

Reverse transcription of M. tuberculosis Rv1630 and Glyceraldehyde-3-Phosphate Dehydrogenase (GAPDH) housekeeping gene was performed using 200 ng RNA in a T100 Thermal Cycler (Bio-Rad). The reaction was carried out with Reverse Transcription Reagents (Applied Biosystems) in a $20 \mu \mathrm{L}$ reaction volume, which contained $4 \mu \mathrm{g}$ of total RNA, retro-transcription buffer $1 \mathrm{X}, 5.5 \mathrm{mM} \mathrm{MgCl}_{2}, 2 \mathrm{mM}$ dNTPs, $0.5 \mu \mathrm{M}$ of reverse primer (primers used are listed in Table 1), $0.4 \mathrm{U} / \mathrm{R}$ RAse inhibitor, $3 \mathrm{U} / \mu \mathrm{L}$ Multi Scribe Reverse Transcriptase, and DEPC treated water. The following thermal parameters were used: 1 cycle to $48^{\circ} \mathrm{C}$ for $45 \mathrm{~min}, 1$ cycle to $95^{\circ} \mathrm{C}$ for $5 \mathrm{~min}$, and the stable phase to $5^{\circ} \mathrm{C}$ for $5 \mathrm{~min}$. To verify that there was no genomic DNA contamination, a reaction without reverse transcriptase was added. qPCR was performed independently using specific primers that hybridize a specific sequence of the $M$. tuberculosis Rv1630 (RpsA) gene but not the homologue gene coding for the RpsA protein of $M$. smegmatis. The primer sequences for qPCR for both the Rv1630 and housekeeping genes are found in Table I. Values obtained were normalized with respect to the housekeeping GAPDH gene using Livak's method (18). Each cDNA was amplified in a LightCycler Nano thermocycler (Roche) using $10 \mu \mathrm{L}$ of LightCycler 480 SYBR Green I Master (1.6 $\mu \mathrm{L}$ of each forward and reverse primer (10 $\mu \mathrm{M}$ concentration), $2 \mu \mathrm{L}$ of $\mathrm{cDNA}$ and $4.8 \mu \mathrm{L}$ of Milliq water), under the following cycling parameters: 1 cycle of $95^{\circ} \mathrm{C}$ for 10 minutes, 40 cycles of $95^{\circ} \mathrm{C}$ for 20 seconds, $60^{\circ} \mathrm{C}$ for 20 seconds and $72^{\circ} \mathrm{C}$ for 35 seconds, 1 cycle of $60^{\circ} \mathrm{C}$ to $95^{\circ} \mathrm{C}$ with a ramp of $0.1^{\circ} \mathrm{C} / \mathrm{s}$, and $1 \mathrm{cycle}$ of $40^{\circ} \mathrm{C}$ for 10 minutes. The cycle threshold (Ct) was calculated using Step One Plus v2.1 Software (Applied Biosystems). The experiment was repeated three times using RNA extracted from three independent cultures. 


\section{Confirmation of RpsA protein expression by Western blot in strains of $M$.} smegmatis:pNIT/RpsA

\section{Cloning of M. tuberculosis H37Rv Rv1630 (RpsA) into pET28a vector}

M. tuberculosis Rv1630 gene sequence (Genbank ID: NC 000962.3) was used to design the primers for cloning in the pET28a vector (primers used are listed in Table 1). Primers contain the restriction sites for the enzymes BamHI and Xhol and provide an aminoterminal $6 \mathrm{His}-$ Tag. Gene amplification was performed using a $25 \mu \mathrm{L}$ final volume PCR master mix containing $1 \mathrm{X}$ PCR buffer, $1.5 \mathrm{mM} \mathrm{MgCl}$,, $0.2 \mathrm{mM}$ dNTPs, $1 \mu \mathrm{M}$ forward and reverse primers and $0.025 \mathrm{U} / \mu \mathrm{L}$ of Taq polymerase. The conditions for the amplification were: an initial denaturation of $95^{\circ} \mathrm{C}$ for $5 \mathrm{~min}$, followed by 35 cycles of a denaturation cycle at $95^{\circ} \mathrm{C}$ for $30 \mathrm{sec}$, an annealing cycle at $62^{\circ} \mathrm{C}$ for $1 \mathrm{~min}$, and an extension cycle at $72^{\circ} \mathrm{C}$ for $90 \mathrm{sec}$. A final extension cycle was performed at $72^{\circ} \mathrm{C}$ for $5 \mathrm{~min}$. Both the pET28a vector and the $R v 1630$ gene amplification product (1446 bp) were purified using the PCR quick spin kit (Roche) following the manufacturer's protocol. They were then digested with BamHI and Xhol and inserted into the pET28a vector using the DNA T4 ligase for 16 hours at $16^{\circ} \mathrm{C}$. The E. coli Novablue cells were transformed by thermal shock treatment using a volume of $5 \mu \mathrm{L}$ of the ligation reaction. Plasmid DNA was extracted from recombinant clones with the High Pure Isolation kit (Roche) as directed by the manufacturer and sequenced in an ABI PRISM 3100 genetic analyzer (Applied Biosystem, Foster City, CA) in both directions.

\section{Expression in E. coli and purification of $M$. tuberculosis H37Rv recombinant RpsA.}

E. coli cells BL21 (DE3) pLysS were transformed by thermal shock treatment using $1 \mu \mathrm{L}$ of the expression vector pET28a cloned with the M. tuberculosis Rv1630 gene. Subsequently, transformed colonies were inoculated in $50 \mathrm{ml}$ of Luria Bertani (LB) broth at $37^{\circ} \mathrm{C}$ overnight. The culture was incubated at 37 degrees for approximately 2 hours until reaching an $\mathrm{OD}_{600}$ of $0.6-0.8 .500 \mu \mathrm{L}$ of Isopropyl $\beta$-D-thiogalactoside (IPTG) was then added at a final concentration of $0.5 \mathrm{mM}$ and this was incubated for 4 hours at $37^{\circ} \mathrm{C}$. 
The cells were separated by centrifugation at $6,000 \mathrm{rpm}$ at $4^{\circ} \mathrm{C}$ for $5 \mathrm{~min}$. The pellet was resuspended in $30 \mathrm{~mL}$ of binding buffer $(20 \mathrm{mM}$ Imidazol, $0.5 \mathrm{M} \mathrm{NaCl}$ and $20 \mathrm{mM}$ phosphate buffer, $\mathrm{pH} 7.4)$ and lysed by repeated thermal shock cycles $\left(-70^{\circ} \mathrm{C}\right.$ to $\left.37^{\circ} \mathrm{C}\right)$ followed by a sonication phase using an Ultrasonic Liquid Processor Homogenizer (Misonix S3000, 3 series of $0.1 \mathrm{sec}$ ON / $0.1 \mathrm{sec}$ OFF for one minute). After centrifugation at $12,500 \mathrm{rpm}$ at $4^{\circ} \mathrm{C}$ for 20 minutes, the supernatant was purified by affinity chromatography using a $5 \mathrm{~mL}$ His-trap column that binds $12 \mathrm{mg} / \mathrm{mL}$ of proteins. The column was then washed with $25 \mathrm{ml}$ binding buffer. RpsA protein bound to the column was eluted using $\mathrm{pH} 7.4$ phosphate buffer with $100 \mathrm{mM}$ imidazole. The $5 \mathrm{ml}$ fractions obtained were combined and concentrated 20 times by filtration with PBS (137 mM NaCl; 2.7 mM KCl; 4.3 mM Na2HPO4; $1.47 \mathrm{mM} \mathrm{KH2PO4),} \mathrm{for} \mathrm{which} \mathrm{a} \mathrm{cellulose} \mathrm{membrane}$ $(10 \mathrm{kDa})$ was used in the Amicon Ultracel (Millipore) ultrafiltration system at $4^{\circ} \mathrm{C}$. The protein concentration was determined by Bradford's reaction, in which a standard curve was constructed using Bovine Albumin Serum (BSA).

\section{Ethics statement, animals and immunization protocol for the production of rabbit} anti-RpsA hyperimmune polyclonal antibodies.

Animal experiments were carried out with strict adherence to the Ethics Commission on Animal Use (CEUA) from the Peruvian University Cayetano Heredia. Two 4-month-old rabbits were immunized four times with $1 \mathrm{mg}$ of recombinant $M$. tuberculosis RpsA protein using Freund's complete adjuvant (FCA). Pre-immune and post-immune serum samples were obtained by collecting approximately $3 \mathrm{~mL}$ of venous blood obtained from the rabbits' ears. After the fourth immunization, 75 days post initial immunization, a final bleed was performed by cardiac puncture under anesthesia $(60 \mathrm{mg} / \mathrm{kg}$ Ketamine, Ket-A10, Alfasan; and $40 \mathrm{mg} / \mathrm{kg}$ Xylazine, Xyl-A-2, Alfasan) to collect an approximate volume of $30 \mathrm{~mL}$ of blood. Once anesthetized, the rabbits were sacrificed with an overdose of Halatal at $20 \mathrm{mg} / \mathrm{kg}$ which was administered intramuscularly. 
An ELISA assay was performed to evaluate whether the post-immune serum contained polyclonal anti-RpsA antibodies. $100 \mu \mathrm{L}$ of recombinant RpsA $(1 \mu \mathrm{g} / \mathrm{mL}, 5 \mu \mathrm{g} / \mathrm{mL}$, and $10 \mu \mathrm{g} / \mathrm{mL}$ ) was fixed in bicarbonate-carbonate buffer at $4^{\circ} \mathrm{C}$ overnight on an ELISA microplate (INMULON Plates). The microplates were washed with $0.05 \%$ PBS-Tween 20 (PBS-T), and each specific coated microplate was blocked using $3 \%$ bovine serum albumin (BSA) and incubated at $37^{\circ} \mathrm{C}$ for 1 hour. The microplates were then washed 5 times with PBS-T, $0.05 \%, 200 \mu \mathrm{L}$ per well. Subsequently, the post immune serum was diluted with $0.05 \%$ PBS-T and $100 \mu \mathrm{L}$ was added to each of the wells and incubated at $37^{\circ} \mathrm{C}$ for 1 hour in a wet chamber environment. The microplates were then washed 5 times with $200 \mu \mathrm{L}$ PBS-T, $0.05 \%$. Subsequently, $50 \mu \mathrm{L}$ of a $1: 50,000$ dilution of HRP antirabbit conjugate $\lg G$ in $5 \%$ skimmed milk powder was added to each well and incubated at $37^{\circ} \mathrm{C}$ for 1 hour. The microplates were washed 5 times with $200 \mu \mathrm{L}$ PBS-Tween 20 , $0.05 \%$. Finally, $50 \mu \mathrm{L}$ of OPD in citrate-phosphate buffer with sodium perborate was

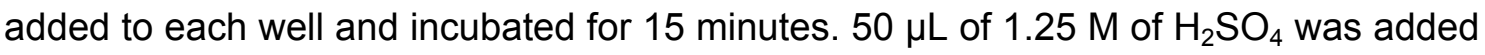
to each well to stop the reactions, and absorption was measured at $595 \mathrm{~nm}$ in an ELISA reader (Spectramax, Molecular Devices).

\section{Western Blotting}

Western blot against the M. tuberculosis RpsA protein was performed to confirm expression of RpsA protein in strains of $M$. smegmatis: pNIT/RpsA. M. smegmatis cultures with two concentrations of IVN inducer $(5$ and $10 \mu \mathrm{M})$ were resolved in a $12 \%$ SDS-PAGE and the proteins transferred to nitrocellulose membranes. Membranes were washed with $0.3 \%$ PBS-Tween and incubated at $4{ }^{\circ} \mathrm{C}$ for 16 hours with the primary hyperimmune polyclonal anti-RpsA antibody diluted in 3\% BSA. Membranes were washed 6 times with $0.3 \%$ BSA-Tween and incubated at $37^{\circ} \mathrm{C}$ for 1 hour with the secondary rabbit anti-lgG antibody marked with Horseradish Peroxidase (HRP). Membranes were washed and revealed with hydrogen peroxide. Finally, the formation 
of the immunocomplexes was visualized using the substrate diaminobenzidine $(1 \mathrm{mg} / \mathrm{mL}$ in citrate buffer, $\mathrm{pH} 5.0$, containing $0.05 \% \mathrm{H}_{2} \mathrm{O}_{2}$ ).

PZA susceptibility testing of induced and uninduced $M$. smegmatis:pNIT/RpsA strains using Tetrazolium Microplate Assay (TEMA).

Susceptibility to PZA was determined by minimum inhibitory concentration (MIC) measurement using the Tetrazolium Microplate Assay (TEMA) (19) for both the induced $(10 \mu \mathrm{M}$ of IVN) and uninduced $M$. smegmatis: pNIT/RpsA cultures. Final well PZA concentrations used were $7500 \mu \mathrm{g} / \mathrm{mL}, 3250 \mu \mathrm{g} / \mathrm{mL}, 1870 \mu \mathrm{g} / \mathrm{mL}, 937 \mu \mathrm{g} / \mathrm{mL}, 468$ $\mu \mathrm{g} / \mathrm{mL}, 234 \mu \mathrm{g} / \mathrm{mL}$, and $117 \mu \mathrm{g} / \mathrm{mL}$. A positive control well containing bacterial suspension without PZA was included. 7H9 broth was enriched with OADC (Oleic acid, albumin, dextrose and catalase) at $\mathrm{pH}$. The plates were incubated for 2 days at $37^{\circ} \mathrm{C}$. After growth in the positive control well on the second day of incubation, $50 \mu \mathrm{L}$ of MTT tetrazolium salt ( $1 \mathrm{mg} / \mathrm{mL}$ ) was added to the well and the plate was incubated for 3 hours. If a yellow to violet color change occurred, this was taken to indicate the viability of $M$. smegmatis and therefore the remaining wells were revealed at this time. MIC was defined as the lowest concentration of the drug where no color change occurred.

\section{RESULTS}

\section{Cloning of M. tuberculosis H37Rv Rv1630 into the pNIT vector}

PCR of transforming colonies following the ligation process between the pNIT vector and the M. tuberculosis Rv1630 gene confirmed the presence of the gene (Figure 1).

\section{Expression of Green Fluorescent Protein into the pNIT vector}

Visualization of GFP fluorescence in the M. smegmatis pNIT-GFP confirmed that the expression vector is producing the recombinant protein appropriately (Figure S1 supplementary material). 


\section{qRT-PCR confirmation of the expression of $M$. tuberculosis Rv1630 in uninduced} and induced strains of $M$. smegmatis:pNIT/RpsA

The uninduced M. smegmatis pNIT/ M. tuberculosis RpsA strain had a Ct value of 27.36 for the Rv1630/RpsA M. tuberculosis gene, while Ct was 13.52 for the induced culture. Ct values for the housekeeping GAPDH gene were 24.63 and 22.24 for the $M$. smegmatis pNIT/M. tuberculosis RpsA strain without induction and for the induced strain, respectively (Table II). The normalized expression of the Rv1630 gene with respect to the housekeeping GAPDH gene resulted in a higher level of expression in the induced strain (Ct-RpsA/Ct-GAPDH $=13.52 / 22.4=0.60)$ compared to the uninduced strain (CtRpsA/Ct-GAPDH $=27.36 / 24.63=1.11)(\mathrm{P}=0.046$, Wilcoxon Rank Test $)$.

\section{Confirmation of RpsA protein expression by Western blot in strains of $M$. smegmatis:pNIT/RpsA}

Recombinant clones were confirmed by the release of fragment Rv1630 from vector pET28a after digestion with appropriate restriction enzymes (Figure 2). Seven recombinant clones were obtained (Vector pET28a/Rv1630). The induced fraction confirmed the presence of the RpsA protein of M. tuberculosis with an estimated weight of 61.2 KDa using SDS-PAGE (Figure 3).

IVN inductor at a concentration of $10 \mu \mathrm{M}$ enabled overexpression of $M$. tuberculosis RpsA in M. smegmatis pNIT/RpsA. RpsA was detected on Western blot as a 61.2-kDa band in the induced culture (Figure 4) and therefore RpsA is predicted to be a $\sim 61.2-\mathrm{kDa}$ protein.

PZA susceptibility testing of induced and uninduced $M$. smegmatis:pNIT/RpsA strains using TEMA (Tetrazolium Microplate Assay).

The TEMA assay confirmed a growth difference between the culture of uninduced versus induced M. smegmatis pNIT/RpsA in the presence of PZA, whereby there is a notable 
inhibition in the growth of induced $M$. smegmatis pNIT/RpsA cultures which express $M$. tuberculosis RpsA (Figure 5).

Evaluations in triplicate on different days show an average MIC reading that confirms a change from a naturally PZA resistant phenotype in $M$. smegmatis (MIC: $>7.5 \mathrm{mg} / \mathrm{mL}$ ) to a phenotype susceptible to PZA (MIC: $0.468 \mathrm{mg} / \mathrm{mL}$ ) in the induced $M$. smegmatis mc²155 pNIT:RpsA M. tuberculosis RpsA ( $\mathrm{P}=0.025$, Wilcoxon Rank Test) (Table III).

\section{DISCUSSION}

In contrast to M. tuberculosis, M. smegmatis is naturally resistant to PZA and is therefore a useful model in which to study PZA resistance mechanisms (20). This study evaluated the effect of introducing M. tuberculosis RpsA into M. smegmatis on PZA sensitivity. We observed a decrease in MIC from $>7500 \mu \mathrm{g} / \mathrm{mL}$ in the uninduced $M$. smegmatis:pNIT:RpsA strain to $468 \mu \mathrm{g} / \mathrm{mL}$ when this strain was induced to produce $M$. tuberculosis RpsA, resulting in a more sensitive phenotype.

M. tuberculosis RpsA was expressed in M. smegmatis using the expression vector pNIT (induced by IVN $10 \mu \mathrm{M}$ ) which shows inducible regulation capacity and a low level of basal expression (21). Western Blot analysis verified that a greater quantity of $M$. tuberculosis RpsA was observed in the induced than in the uninduced $M$. smegmatis strain. This is similar to previous findings following expression of the M. tuberculosis protein PknA in M. smegmatis (22). The pNIT vector has also previously been used to perform functional complementation tests; for example, Li et al. were able to evaluate the importance of the mutant protein PknA K42M for growth in M. smegmatis (23). Another physiological study used pNIT to evaluate the role of PstP phosphatase proteins in the growth of the pathogen within the host. In this study, overexpression of the PstP gene in $M$. smegmatis led to an elongation of the cells (24). 
Given that the RpsA proteins of M. tuberculosis and M. smegmatis share over $90 \%$ of their identity, it is likely that when $M$. smegmatis expresses the foreign RpsA protein from M. tuberculosis, a heterologous complementation process within the ribosome takes place generating groups of both native and hybrid/chimeric ribosomes. There have been studies in which the feasibility of this process has been evidenced; for example, heterologous complementation of yeast ribosomes with ribosomal proteins from plants and mammals $(25,26)$, of fungi with human ribosomal proteins $(27)$, and even of ribosomes from organisms of different domains such as $E$. coli and rats $(28,29)$ have been analyzed using this same approach. In these latter cases it is important to highlight that hybrid ribosomes acquire certain functional characteristics of eukaryotic ribosomes, and therefore it is expected in our study that hybrid ribosomes in $M$. smegmatis would acquire characteristics of a ribosome from $M$. tuberculosis. In addition, there are studies in which heterologous complementation of other enzymes has been analysed $(30,31$, 32, 33); for example, Konse-Thomas et al. evaluated the RNA polymerase synthesis activity of different RNA polymerase hybrids formed from subunits from $E$. coli and $S$. marcescens (30).

Our previous studies showed that there is an association between PZA resistance and POA efflux rate, which correlates with extracellular POA concentration (11). In $M$. smegmatis, resistance to PZA is associated to a POA efflux rate 900 times faster than that of $M$. tuberculosis, which prevents its intracellular accumulation and acidification of the cytosol and thus contributing to resistance to PZA. In a study performed by Boshoff et al. the gene encoding one of the two M. smegmatis pyrazinamidases ( $p z a A)$ was overexpressed and this led to a decrease in the MIC from $>2,200 \mu \mathrm{g} / \mathrm{mL}$ to $150 \mu \mathrm{g} / \mathrm{mL}$ (34). This suggests that the production of POA at high levels due to PZAse overexpression leads to sufficient accumulation in the cytoplasm to cause a change in PZA susceptibility of the organism. Similarly, our results suggest that accumulation of free M. tuberculosis RpsA would enable the retention of intracellular POA, affecting PZA 
susceptibility. Consequently, the difference in amino acid composition of $M$. smegmatis RpsA compared to the recombinant $M$. tuberculosis RpsA may contribute to the natural resistance of $M$. smegmatis to PZA. This inference is consistent with the proposed mechanism for PZA resistance in M. tuberculosis described by Shi et al. (2019) (35). The trans-translation mechanism, which involves the RpsA protein, is more important in slow-growing mycobacteria (i.e. M. tuberculosis) than in fast-growing mycobacteria (i.e. M. smegmatis) where it is considered to be dispensable. However our results showed that expression of the M. tuberculosis ribosomal protein in M. smegmatis led to inhibition of growth in the presence of PZA, suggesting that trans-translation may indeed also be of importance in these mycobacteria. Further studies are needed to evaluate recombinant $M$. tuberculosis RpsA in hybrid/chimeric ribosomes during trans-translation in M. smegmatis and its effect on PZA MIC reduction. These data may then be used to infer the relationship between RpsA structure and function and PZA resistance in $M$. tuberculosis.

\section{ETHICAL STATEMENT}

Ethical approval for rabbit serum collection was obtained from the institutional Ethics Committee of Universidad Peruana Cayetano Heredia with code 66397 (CIEA-Session 09 March 2016).

\section{ACKNOWLEDGEMENTS}

We thank Christopher M. Sassetti and Amit K. Pandey for their kind gifts of pNIT-GFP.

\section{FINANCIAL SUPPORT}

This research was funded by the Wellcome Trust Intermediate Fellowship (grant 099805/Z/12/Z), and by the ERANET LAC ELAC2014/HID-0352, CONCYTECFONDECYT-Peru 086-2015. PS was supported by a Wellcome Trust Intermediate Fellowship. DEK is supported by an MRC Clinical Research Training Fellowship.

\section{COMPETING INTERESTS}

None of the authors have any competing interests. 


\section{REFERENCES}

1. Mitchison D. The action of antituberculosis drugs in short-course chemotherapy. Tubercle. 1985 Sep;66(3):219-25.

2. Zhang Y, Yew W, Chang K. Pyrazinamide Susceptibility Testing in Mycobacterium tuberculosis: a Systematic Review with Meta-Analyses. 2011 Oct;55(10):4499-505.

3. Zhang $\mathrm{Y}$, Mitchison D. The curious characteristics of pyrazinamide: a review. Int J Tuberc Lung Dis. 2003 Jan;7(1):6-21.

4. Lamont E, Dillon N, Baughn A. The Bewildering Antitubercular Action of Pyrazinamide. Microbiology and Molecular Biology Reviews. June 2020 Volume 84 Issue 2 e00070-19

5. Lamont E, Dillon N, Baughn A. Impact of the host environment on the antitubercular action of pyrazinamide. EBioMedicine. October 25 2019;6:1

6. Peterson N, Rosen B, Dillon N, Baughn A. Uncoupling environmental $\mathrm{pH}$ and Intrabacterial acidification from pyrazinamide Susceptibility in Mycobacterium tuberculosis. Antimicrobial Agents and Chemotherapy. December 2015 Volume 59 Number 12.

7. Wu X, Zhang J, Zhong M. Studies on pncA gene mutations in M. tuberculosis isolates. Zhonghua Jie He Hu Xi Za Zhi. 2000 Jan;23(1):40-2.

8. Sheen P, Ferrer P, Gilman RH, Lopez-Llano J, Fuentes P, Valencia E, et al. Effect of pyrazinamidase activity on pyrazinamide resistance in Mycobacterium tuberculosis. Tuberculosis (Edinb). 2009Mar;89(2):109-13.

9. Mestdagh M, Realini L, Fonteyne PA, Rossau R, Jannes G, Mijs W, De Smet KA, Portaels $F(2000)$. Correlation of pncA sequence with pyrazinamide resistance level in BACTEC for 21 Mycobacterium tuberculosis clinical isolates. Microb Drug Resist 6; 283287

10. Zimhony O, Cox J, Welch J, Vilchèze C. and Jacobs, W. Pyrazinamide inhibits the eukaryotic-like fatty acid synthetase I (FASI) of Mycobacterium tuberculosis. Nat. Med. 6, 1043-1047 (2000). 
11. Shi W, Chen J, Feng J, Cui P, Zhang S, Weng X, Zhang W and Zhang Y (2014). Aspartate decarboxylase (PanD) as a new target of pyrazinamide in Mycobacterium tuberculosis. Emerging Microbes and Infections 3; 58.

12. Sheen et al. A multiple genome analysis of Mycobacterium tuberculosis reveals specific novel genes and mutations associated with pyrazinamide resistance. 2017 Oct 11;18(1):769.

13. Guo M., Sun Z, Zhang Y. Mycobacterium smegmatis has two Pyrazinamidase enzymes, PncA and PzaA. Journal of bacteriology. 2000. p. 3881-3884

14. Zimic M, Fuentes P, Gilman RH, Gutierrez AH, Kirwan D, Sheen P. Pyrazinoic acid efflux rate in Mycobacterium tuberculosis is a better proxy of pyrazinamide resistance. Tuberculosis. 2012; 92: 84-91.

15. Shi W, Zhang X, Jiang X, Yuan H, Lee J, Barry C, et al. Pyrazinamide inhibits transtranslation in Mycobacterium tuberculosis. Science. 2011 Sep 16;333(6049):1630-2.

16. Yang,J., Liu,Y., Bi,Y., Cai,Q., LiaoX., Li,W., Guo,Ch., Zhang,Q., Lin,T., Zhao,Y., Wang,H., Liu,J., Zhang,X. and Lin,D. Structural basis for targeting the ribosomal protein S1 of Mycobacterium tuberculosis by pyrazinamide. Mol Microbiol. 2015. 95(5):791-803. 17. Keiler K. Biology of trans-translation. Annual Rev Microbiol. 2008; 62:133-51.

18. Livak KJ, Schmittgen TD. Analysis of relative gene expression data using real-time quantitative PCR and the 2(-Delta C(T)) Method. Methods. diciembre de 2001;25(4):4028.

19. Caviedes L, Delgado J, Gilman RH. Tetrazolium microplate assay as a rapid and inexpensive colorimetric method for determination of antibiotic susceptibility of Mycobacterium tuberculosis. J Clin Microbiol 2002;40:1873-4.

20. Boshoff $H$, Mizrahi V.. Expression of Mycobacterium smegmatis pyrazinamidase in Mycobacterium tuberculosis confers hypersensitivity to pyrazinamide and related amides. J Bacteriol. 2000 Oct;182(19):5479-85. 
21. Pandey, A.; Raman, S.; Proff, R.; Joshi, S.; Kang, C.; Rubin, E. and et al. Nitrileinducible gene expression in mycobacteria. Tuberculosis. 2009. Vol. 89. $\mathrm{N}^{\circ} 12-16 . \mathrm{Pp}$ 12-16.

22. Sathya Narayanan Nagarajan, Sandeep Upadhyay, Yogesh Chawla, Shazia Khan, Saba Naz, Jayashree Subramanian, Sheetal Gandotra and Vinay Kumar Nandicoori. Protein Kinase A (PknA) of Mycobacterium tuberculosis Is Independently Activated and Is Critical for Growth in Vitro and Survival of the Pathogen in the Host. The Journal of Biological Chemistry. 2015. Vol. 290, NO. 15, pp. $9626-9645$.

23. Li, W, Zhao Q, Deng W, Chen T, Liu M. Mycobacterium tuberculosis Rv3402c Enhances Mycobacterial Survival within Macrophages and Modulates the Host ProInflammatory Cytokines Production via NF-Kappa B/ERK/p38 Signaling. PLoS ONE. 2014. 9(4): e94418. doi:10.1371/journal.pone.0094418

24. Aditya K. Sharma, Divya Arora, Lalit K. Singh, Aakriti Gangwal, Andaleeb Sajid, Virginie Molle, Yogendra Singh, and Vinay Kumar Nandicoori. Serine/threonine protein phosphatase PstP of Mycobacterium tuberculosis is necessary for accurate cell division and survival of pathogen. The Journal of Biological Chemistry. 2016. Vol. 291, N 46, pp. 24215-24230.

25. Fleming, G.; Belhumeur, P.; Skup, D. and Fried, H. Functional substitution of mouse ribosomal protein L27' for yeast ribosomal protein L29 in yeast robosomes. Protc. Natl. Acad. Sci. 1989. Vol 86. pp 217-221.

26. Dick, F. and Trumpower, L. Heterologous complementation reveals that mutant alleles of QSR1 render 60S ribosomal subunits unstable and translationally inactive. Nucleic Acids Research. 1998. Vol. 26. № 10. pp 2442-2448.

27. Dequard-Chablat, M. and Rötig, A. Homologous and heterologous expression of a ribosomal protein gene in Podospora anserina requires an intron. Molecular and General Genetics. 1997. Vol. 253. pp $546-552$.

28. Uchiumi, T.; Hori, K.; Nomura, T. and Hachimori, A. Replacement of 7/L12.L10 Protein Complex in Escherichia coli Ribosomes with the Eukaryotic Counterpart 
Changes the Specificity of Elongation Factor binding. The Journal of Biological Chemistry. 1999. Vol. 274. №39. pp 27578-27582.

29. Uchiumi, T.; Honma, S., Nomura, T., dabbs, E. and Hachimori, A. Translation elongatio by a Hybrid Ribosome in Wich Proteins at the GTPase Center of the Escherichia coli Ribosome Are Replaced with Rat counterparts. The Journal of Biological Chemistry. 2001. Vol. 277. N 6. pp 3857-3862.

30. Konse-Thomas, B. and Ruger, W. Functional Hybrid Enzymes Reconstituted from Escherichia coli and Serratia marcescens RNA Polymerase Subunits. Eur. J. Biochem. 1976. Vol, 63. Pp 321-329.

31. Lawrence, N.; Richman, A.; Amini, R.; and Altman, S. Heterologous enzyme function in Escherichia coli and the selection of genes encoding the catalytic RNA subunit of RNaseP. Proc. Natl. Acad. Sci. 187. Vol 84. Pp 6825 - 6829.

32. Wang, Y., Zhou, J., Wang, Y., Bao, J. and Chen, H. Properties of Hybrid Enzymes between Synechococcus Large Subunits and Higher Plant Small subunits of Ribulose1,5-biphosphate Carboxylase/Oxygenase in Escherichia coli. Archives of Biochemistry and biophysics. 2001. Vol 396. N 1. Pp 35-42.

33. Jun, D., Huang, V. and Beatty, T. Heterologous production of thermophile Thermochromatium tepidum photosynthetic reaction centre and light harvesting I complex in the mesophile Rhodobacter sphaeroides and thermal stabilities of a hybrid core complex. Appl. Environ Microbiol. 2017. Vol 83. N² 20. E01481-17

34. Boshoff H, Mizrahi V. Purification, Gene Cloning, Targeted Knockout, Overexpression, and Biochemical Characterization of the Major Pyrazinamidase from Mycobacterium smegmatis. J Bacteriol. 1998 Nov; 180(22): 5809-5814.

35. Shi, W.; Cui, P.;Niu, H;Zhang, S; Tonjum, T; Zhu, B; Zhang, Y. Introducing RpsA point mutation $\triangle 438 \mathrm{~A}$ or $\mathrm{D} 123 \mathrm{~A}$ into the chromosome of $\mathrm{M}$. tuberculosis confirms its role in causing resistance to pyrazinamide. Antimicrob Agents Chemother. 2019. 


\section{TABLES}

Table I.- Strains, plasmids and oligos used in this study

\begin{tabular}{lcc}
\hline \multicolumn{1}{c}{ Strains/Plasmids / Oligos } & Description & Source \\
\hline Strains: & K-12 strain ideally suited as an initial cloning host & Novagen \\
E. coli Novablue & Most widely used host background for protein & Novagen \\
& expression & \\
E. coli BL21 (DE3) plysS & & Gift from \\
& & Johns \\
& & Hopkins \\
& & Bloomberg \\
Mycobacterium smegmatis mc ${ }^{2} 155$ & High-frequency transformation strain & School of \\
& & Public \\
& & Health
\end{tabular}

Plasmids:

pET28a-RpsA

pNIT-GFP

pNIT-RpsA
Pet28a vector containing MTB Rv1630 gene in its multiple cloning site

pNIT vector containing GFP gene in its multiple cloning site

pNIT vector containing MTB Rv1630 gene in its multiple cloning site
Present study

Gift from Christopher M. Sassetti and Amit K. Pandey

Present study

Oligonucleotides:

Rpsa MTB_pET28 Fw

5' ATAGgATCCATGCCGAGTCCCACCGTCAC 3'

Present study

Rpsa MTB_pET28 Rv

5' ATTCTCGAGTCAAGCGCTGCCGGCGAGTT 3'

Present study

Rpsa MTB_pNIT TB Fw

5'ATACCATATGATGCCGAGTCCCACCGTCAC 3'

Present study

RpsA MTB_pNIT TB Rv

Present study 
RpsA TB RT-Fw

RpsA TB RT-Rv

GAPDH MSMEG RT-Fw

GAPDH MSMEG RT-Rv
5' CAACTACATCTTCCC 3'

5' CCAGCCGCCTCGGCG 3'

5'CGGCAGCCAGAACATCATCT 3'

5' CGGGCCCAGGCAGTT 3'

\section{Present study \\ Present study \\ Present study \\ Present study}

\section{Tabla II.- Expression of Rv1630 gene in Mycobacterium smegmatis $\mathrm{mc}^{2} 155$ as} determined by qPCR Real-time

\begin{tabular}{|c|c|c|c|}
\hline \multicolumn{2}{|l|}{ Gene } & \multicolumn{2}{|l|}{ Cycle threshold $(\mathrm{Ct})$ values } \\
\hline & $\begin{array}{c}\text { Mean CT } \\
\text { (MSMEG \# Rv1630 IND) }^{a} \\
\text { (A) }\end{array}$ & $\begin{array}{c}\text { Mean CT } \\
\text { (MSMEG \# Rv1630 NON-IND) }^{\text {b }} \\
\text { (B) }\end{array}$ & $\begin{array}{c}\Delta C T \\
\text { (Rv1630 IND \& } \\
\text { Rv1630 NON-IND) } \\
\text { (B)-(A) }\end{array}$ \\
\hline $\begin{array}{l}\text { Rv1630 (M. } \\
\text { tuberculosis RpsA) }\end{array}$ & 13.52 & 27.36 & 13.84 \\
\hline GAPDH & 22.24 & 24.63 & 2.39 \\
\hline \multicolumn{3}{|c|}{ Relative nomalized difference in expression $(\Delta \Delta C T)$} & 11.45 \\
\hline
\end{tabular}


M. smegmatis $\mathrm{mc}^{2} 155$

PZA

$>7500$

$>7500$

468

a $M$. smegmatis $\mathrm{mc}^{2} 155$ containing induced recombinant vector (MSMEG-pNIT-MTB Rv1630);

b $M$. smegmatis $\mathrm{mc}^{2} 155$ containing non-induced recombinant vector (MSMEG-pNIT-MTB Rv1630); PZA, Pyrazinamide; MIC, minimum inhibitory concentration.

\section{FIGURES}

\section{FIGURE LEGENDS}

Figure 1. PCR Colony used to verify the insertion of the Rv1630 gene (M. tuberculosis RpsA) in the pNIT vector. Rv1630 gene: $1446 \mathrm{pb}$. Line 1-10: C1-C10. M: 1Kb plus marker (invitrogene). C: Clone.

Figure 2. Electrophoresis in $1 \%$ agarose gel stained with ethidium bromide. Enzymatic digestion used to test the insertion of the Rv1630 gene (M. tuberculosis RpsA) in the pET28a vector. Rv1630 gene: 1446 pb. M: 1Kb plus marker (invitrogene). Line 1: Nondigested Plasmid (Clone 1), Line 2: Plasmid + BamHI, Line 3: Plasmid + BamHI/Xhol, Line 4: Non-digested Plasmid (Clone 2), Line 5: Plasmid + BamHI, Line 6: Plasmid + BamHI/Xhol. 
Figure 3. Electrophoresis SDS-PAGE 12\% (SDS-PAGE). Expression and purification of the RpsA protein (M. tuberculosis Rv1630) in E. coli using the pET28a expression vector. IND: Crude extract (induced sample), NI: Crude extract (Non-induced sample), Line 1-3: Purified fractions (100 mM Imidazol), M: Broad Range protein marker (Biorad), Line 4-6: Purified fractions (100 mM Imidazol).

Figure 4. Western Blot against the M. tuberculosis protein RpsA. Line 1: Empty; Line 2: Culture of Non-induced M. smegmatis mc $\mathrm{m}^{2155}$. Line 3: Culture of $M$. smegmatis $\mathrm{mc}^{2155}$ induced with $5 \mu \mathrm{M}$ of IVN. Line 4: Culture of M. smegmatis $\mathrm{mc}^{2155}$ induced with $10 \mu \mathrm{M}$ of IVN. M: Dual Color protein marker (Biorad). Estimated size of the M. tuberculosis protein RpsA: $61.2 \mathrm{Kda}$.

Figure 5. MIC of PZA in cultures of $M$. smegmatis using the TEMA assay. Line $1, M$. smegmatis $\mathrm{mc}^{2} 155$ WT without plasmid. Line 2, M. smegmatis mc 2155 pNIT:RpsA Noninduced plasmid. File 3, M. smegmatis $\mathrm{mc}^{2} 155$ with pNIT:RpsA plasmid induced with 10 $\mu \mathrm{M}$ IVN. Row $4, M$. smegmatis mc 2155 with pNIT:RpsA plasmid induced with $10 \mu \mathrm{M}$ IVN (duplicate). PZA serial dilutions from $7500 \mu \mathrm{g} / \mathrm{ml}$ to $117 \mu \mathrm{g} / \mathrm{ml}$ are shown. GC: Positive growth control in a drug-free $7 \mathrm{H} 9$ Broth.

Figure S1 - SUPPLEMENTARY MATERIAL. Cultures of M. smegmatis mc ${ }^{2155}$ with recombinant vectors $p$ NIT/RpsA and vector pNIT/GFP without exposure to UV light (A) and with exposure to UV light (B). 
61.2 KDa -

75 KDa

$-50$

$-25$

Figure 4 
Pyrazinamide $(\mu \mathrm{g} / \mathrm{ml})$
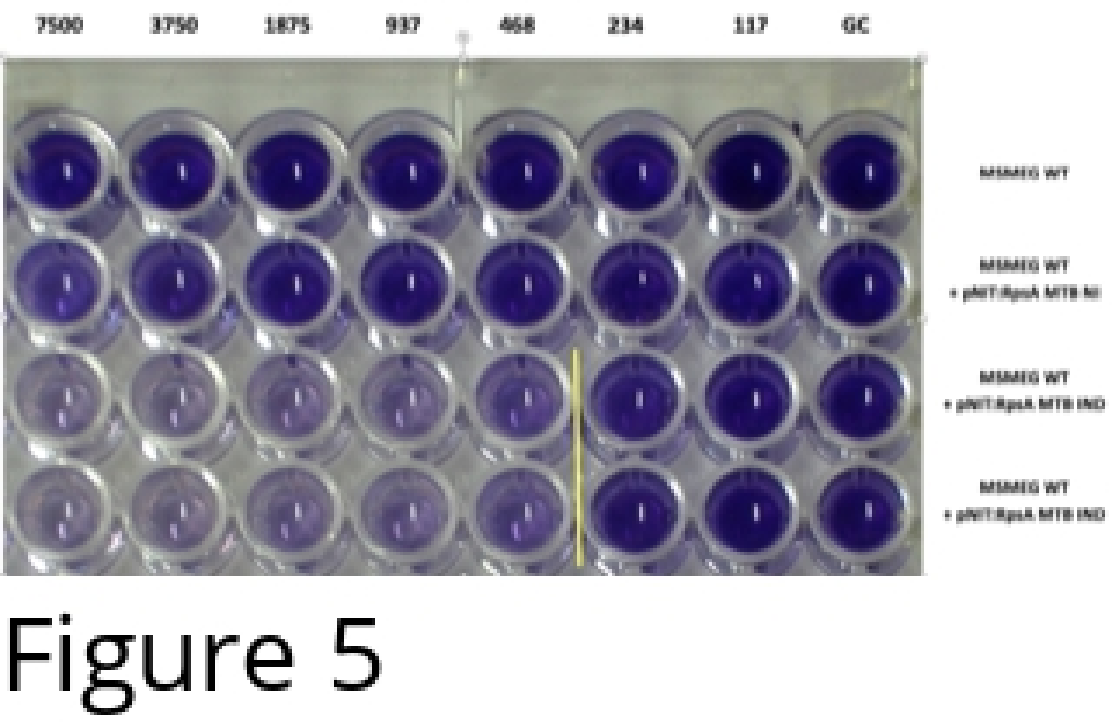


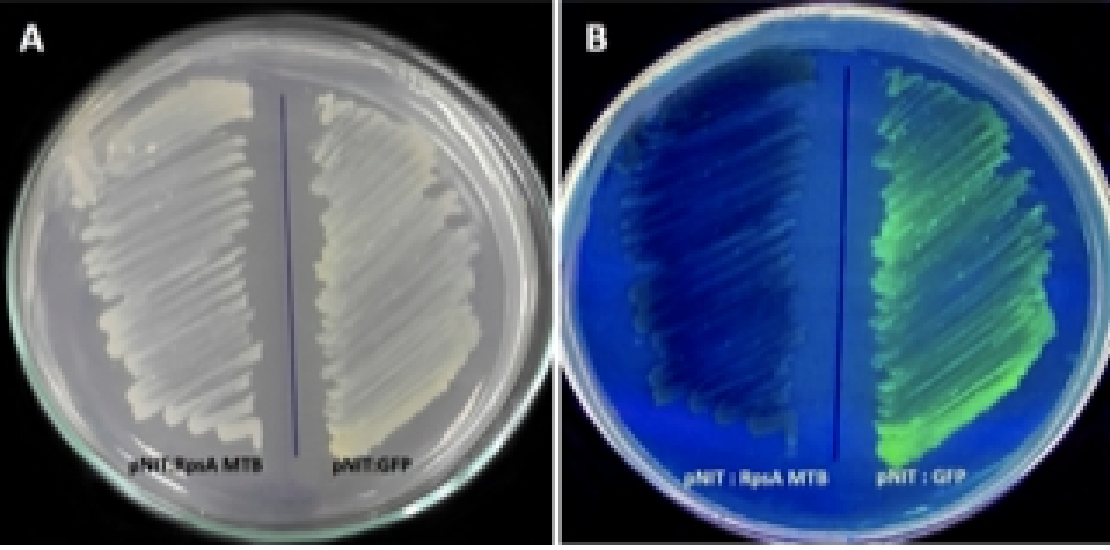

Figure S1 


\section{$\begin{array}{lllllllllll}1 & 2 & 3 & 4 & 5 & 6 & 3 & 4 & 5 & 6 & M\end{array}$}

$1446 \mathrm{pb}$

Figure 1 
$2000 \mathrm{ph}=$ 1650 -

$1000=$

Figure 2 
